\title{
Making mental health an integral part of sustainable development: the contribution of a social determinants framework
}

\author{
M. J. De Silva* \\ Centre for Global Mental Health, London School of Hygiene \& Tropical Medicine, Keppel Street, London WC1E 7HT, UK
}

\begin{abstract}
There have been repeated calls to include mental health in the sustainable development goals (SDGs), arguing that progress in development will not be made without improvements in mental health. Although these calls are starting to gain political traction, currently only a tiny fraction of international development work includes mental health. A social determinants framework may be useful in incorporating mental health into sustainable development because it promotes a multi-sectorial and multi-disciplinary approach which is the corner stone of good development practice. Two approaches are suggested to make mental health a part of sustainable development: (1) integrate mental health into existing development programmes to promote social and economic environments that prevent mental health problems developing; (2) ensure that mental health programmes are better at promoting sustainable development by preventing the negative social and economic consequences of mental illness. Real-world examples of these approaches are provided. To achieve this, the mental health impact of wider development programmes, and the social and economic consequences of mental health interventions, must be evaluated. Development agencies should ensure that they have equity for mental health in all their policies, and investment must be increased for those mental health prevention, promotion and treatment programmes which have the greatest impact on sustainable development. The SDGs bring the promise of a more holistic approach to development. It is now the task of global mental health to demonstrate not just that mental health is an integral part of sustainable development, but that affordable and effective solutions exist which can improve mental health and development more broadly.
\end{abstract}

\section{Why mental health is a critical part of sustainable development}

There have been repeated and increasingly frequent calls to include mental health in the sustainable development goals (SDGs). This is for the simple reason that progress in development will not be made without improvements in mental health (De Silva et al. 2014). The arguments for why mental health must be a part of the SDGs have been powerfully made (Lund, 2013; Eaton et al. 2014; Thornicroft \& Patel, 2014), and can be summarised as the health case, the social and economic case and the human rights case (De Silva et al. 2014).

\section{The health case}

Mental health problems cause $22.9 \%$ of all Years Lived with Disability, the highest burden of any health condition (Whiteford et al. 2013). They cause excess and avoidable mortality which has been described as a form of 'lethal discrimination' (Thornicroft, 2013). A study in

* Address for correspondence: M. J. De Silva, Centre for Global Mental Health, London School of Hygiene \& Tropical Medicine, Keppel Street, London WC1E 7HT, UK.

(Email: mary.desilva@1shtm.ac.uk)
Ethiopia found that people with severe mental health problems had life expectancies 30 years shorter than those without (Fekadu et al. 2015), while globally, nearly 1 million people take their own lives every year (WHO, 2013c), Nearly three quarters of people with mental health problems live in low and middle income countries (WHO, 2010), where on an average less than 1 in 10 will receive evidence-based treatment (Kohn et al. 2004).

\section{The economic and social case}

Mental health problems impose a tremendous economic and social cost to society that places a brake on development efforts. The estimated costs of mental health problems are staggering at US\$2.5 trillion in 2010, rising to US $\$ 6.0$ trillion per annum by 2030 (Bloom et al. 2011). These costs are due to reduced economic productivity, high rates of unemployment, under-performance at work and often catastrophic out of pocket health expenditure (Bloom et al. 2011; WHO, 2013b).

Poverty and mental health problems are intimately related to one other, with those living in poverty more likely to develop mental health problems, and mental health problems leading to a downward spiral 
of economic disenfranchisement (WHO, 2005; Bloom et al. 2011). This is particularly true in poorer countries, where the absence of a welfare safety net and lack of access to effective treatments accelerate the cycle of disadvantage.

\section{The human rights case}

Outdated laws leading to discrimination, stigma, and poor access to services, mean that people with mental health problems are more likely to experience social exclusion, violent victimisation and human rights abuse, described as a 'failure of humanity' (Kleinman, 2009).

\section{Increasing political attention to mental health}

The arguments for why mental health should be included in the SDGs are starting to gain political traction. There is now a concerted campaign FundaMentalSDG - lobbying for the inclusion of a mental health target and associated indicators within the health goal of the SDGs (Thornicroft \& Patel, 2014). In the UK, the 2014 International Development Committee Inquiry into Disability and Development recommended that the Department for International Development (DFID) 'thoroughly appraise the case' for spending more on mental health and explain its reasons if it decides against increasing funding (House of Commons International Development Committee, 2014). Subsequently, a report by the UK All Party Parliamentary (APPG) Global Health and Mental Health Groups makes clear recommendations that DFID should 'integrate', 'evaluate' and 'replicate' mental health in its programmes, and that they should lobby for the inclusion of a mental health target in the health goal of the SDGs (De Silva et al. 2014). The forthcoming World Bank and World Health Organisation (WHO) meeting on depression presents a further opportunity to make mental health an integral part of sustainable development.

These developments come in the context of universal ratification by all 194 member states of the WHOs Mental Health Action Plan 2013-2020 (WHO, 2013a). All countries have committed to achieve four objectives comprising: strengthening effective leadership for mental health; providing mental health and social care in community-based settings; implementing promotion and prevention strategies; and strengthening information systems, evidence and research for mental health. All objectives have corresponding global targets to be achieved by 2020, and associated indicators to measure progress. The Action Plan provides a clear road map of what needs to be achieved. The question is how to achieve these goals in practice.

\section{The current place of mental health in development}

This increasing political attention is critical, for currently almost no international development work includes mental health.

\section{International development agencies and NGOs}

DFID are one of the few government agencies to have a mental health portfolio, though they have been criticised for having a small number of isolated projects with no coherent or strategic understanding of how mental health should factor into their wider health and development work (De Silva et al. 2014). Though DFID states that its focus is on ensuring that mental health is included in its work on health systems strengthening (House of Commons International Development Committee, 2014), there are only a few examples of this happening. These comprise projects in individual countries, such as in Ghana where $£ 7$ million has been allocated over five years to support direct service improvements and policy development (De Silva et al. 2014).

There are an astonishingly small number of international NGOs who work exclusively in mental health. Notable examples include BasicNeeds, who work in 11 countries in Africa and Asia to deliver their Mental Health and Development Model which combines health, socio-economic and community oriented solutions with changes in policy, practice and resource allocation (Raja et al. 2012; BasicNeeds), and the Peter C. Alderman Foundation who work with governments in Uganda, Kenya and Cambodia to establish trauma clinics delivered through public-private partnerships in postconflict settings (Nakimuli-Mpungu et al. 2013; PCAF).

As part of the APPG report, all the major UK NGOs were contacted and asked if they included mental health as part of their wider work. Few could name any projects, or reported measuring the mental health impacts of their wider development programmes. Exceptions included VSO, International Medical Corps and the Tropical Health Education Partnership (De Silva et al. 2014). There are also a small number of international NGOs including CBM International who work with local partners to deliver a wide range of programmes for people with physical and psychosocial disabilities (Cohen et al. 2011). CBM use an integrated approach to mental health care, Community Based Rehabilitation (CBR), which may have a wider impact on outcomes which promote sustainable development. 


\section{Research funding bodies}

There are still only a handful of funders who support research essential to understand how development could be promoted through increasing access to costeffective mental health services in low resource settings. The Canadian Government are world leaders with their pioneering Grand Challenges Canada Global Mental Health programme which to date has funded CAN \$29.9 million to 61 projects in 26 countries. These grants are building the capacity of a new generation of mental health researchers and practitioners in low and middle-income countries, on whom the task of scaling up mental health services will largely fall. Grand Challenges Canada also support the Mental Health Innovation Network (www.mhinnovation.net) which facilitates the exchange of information about effective programmes between researchers, practitioners and policy makers, and aims to increase the international profile of global mental health.

DFID are also ahead of the curve through their support of two Research Partnership Consortiums. Starting in 2005, the Mental Health and Poverty Project provided new knowledge on comprehensive multi-sectorial approaches to breake the cycle of poverty and mental health in four African countries (Flisher et al. 2007). Since 2011, the PRogramme for Improving Mental health carE (PRIME) has been designing, evaluating and scaling up district level mental health care plans in Ethiopia, India, Nepal, South Africa and Uganda (Lund et al. 2012). Apart from these, there are only a handful of other international funders such as the Wellcome Trust (one of the earliest supporters of global mental health research), the National Institute of Mental Health, USAID and the European Union who can name a small number of global mental health projects that they support. Though the funding environment has improved over the last 5 years, it remains to be seen whether the recent increased political attention afforded to mental health will translate into improved funding for much needed research.

\section{Using social determinants to integrate mental health into development practice}

Plagerson has argued for the mutual benefit of mental health and social development, drawing on a capabilities framework (Sen, 1999) to understand both the intrinsic value of mental health as development end in itself, and mental health as a constituent component of development (Plagerson, 2014). To convert this to effective action, the field of global mental health needs to demonstrate both how to integrate mental health into existing development programmes, and how to ensure that mental health programmes are better at promoting sustainable development. A social determinants framework may be extremely useful in achieving this because it promotes a multi-sectorial and multi-disciplinary approach which is the corner stone of good development practice.

As Pearlin so eloquently puts it: 'Well-being is affected by the structured arrangements of people's lives and by the repeated experiences that stem from these arrangements' (Pearlin, 1989), emphasising the critical importance of the social world in disease causation. Understanding the social determinants of mental health has much to offer the development agenda, going well beyond just understanding the aetiology of disorders. As Rose (1992) states: 'the primary determinants of disease are mainly economic and social, and therefore its remedies must also be economic and social' (Rose, 1992).

I suggest two solutions to achieve integration of mental health into broader development work. These solutions pivot on the vicious cycle of poverty and mental illness. Research has shown that this cycle can be broken by combating the social causation of mental illness through antipoverty interventions, and by mitigating some of the negative social and economic effects of mental illness by preventing people with mental health problems drifting into poverty (Lund et al. 2011).

\section{Solution 1: integrate mental health into existing development programmes to prevent mental health problems developing}

Many development programmes may impact mental health, either in a positive or a negative way. The strong relationship between mental health and many of the Millennium Development Goals illustrates how initiatives to promote education, gender equality, improve maternal and child health, and eradicate extreme poverty and hunger may have knock-on positive effects on mental health, and equally how poor mental health (such as maternal depression) may decelerate progress towards these goals (for example by reducing child immunisation rates) (Miranda \& Patel, 2005).

Interventions which target the social causes of mental illness include poverty alleviation through financial instruments such as grants, small loans and conditional cash transfers; increasing food and water security; and promoting safer and more secure living environments (Lund, 2013). A recent report on the social determinants of mental illness recommends social welfare for the unemployed, targeting families of people with mental disorders in poverty alleviation programmes, policies restricting the availability of alcohol, microfinance schemes and improvements in housing and particularly in promising development policies which 
may improve mental health. The report argues that these social and economic risk factors have particularly strong associations with mental health and a clear social class gradient, so intervening on these may have the greatest impact on reducing inequalities in health (WHO \& Calouste Gulbenkian Foundation, 2014).

The problem is that evaluations of development programmes almost never measure mental health outcomes. When such evaluations have been conducted, they show both positive and negative unintended consequences on the mental health of the recipients. A good example of this is the mixed and unintended effect that poverty alleviation schemes can have on mental health. While there is scant (though growing) evidence about the effect of such schemes, the evidence that does exist suggests that cash transfers conditional on school attendance can have a positive effect on child mental health, unconditional cash transfers seem to have no effect, and small loans a negative effect on stress levels (Lund et al. 2011).

There is a clear need for mental health to create a dialogue with other disciplines to show that mental health can be measured by existing quick and reliable measurement tools. Core outcomes are being developed for depression and anxiety by the International Consortium for Health Outcomes Measurement (http:// www.ichom.org/). This exercise needs to be repeated for other mental disorders to provide a standard set of outcome indicators which can be used to assess the mental health impact of development programmes. Another promising development is a project by the Mental Health Innovation Network (www.mhinnovation.net) to systematically review the validity of different screening tools for common mental disorders in all low and middle income countries. A searchable online database will be created which will allow users from any discipline to quickly locate the most valid tool to screen for a particular disorder in a given setting.

There are good examples of non-health policies which have had a profound impact on mental health, illustrating that just as the risk and protective factors for mental illness operate across different sectors (education, social, health, work place, livelihoods and the physical environment), and at different levels (individual, family, community, district, national and international), interventions to target them must also be multi-level and cross-sector. A powerful example of this is the 8-fold increase in suicide rates in Sri Lanka between 1950 and 1995, attributed to rapid social change and the ethnic war. In 1995, Sri Lanka set up a Presidential Commission, resulting in a ban on the sale of all pesticides which are highly toxic to humans. The Ministry of Agriculture worked with industry to implement the ban slowly over 2-3 years, and provided advice to farmers on locally acceptable alternative practices. As a result, the total number of suicides fell by 50\% from 1996-2005 compared to 1986-1995, a reduction of approximately 19800 suicides. The ban was shown to be acceptable to farmers and to have minimal effect on agricultural costs or crop yields (Gunnell et al. 2007).

Solution 2: ensure that mental health programmes are better at promoting sustainable development to prevent the negative social and economic consequences of mental illness.

A clear area for intervention using a social determinants approach is prevention and early intervention, to prevent many of the lasting negative economic and social consequences of mental illness. Understanding social determinants allow targeted programmes to be developed, such as for expectant mothers living in poverty and experiencing domestic abuse, or people who have experienced forced migration. There are good examples of programmes which promote social and economic development through preventing mental health problems developing in children and young people. These include the KIDS project in Kenya - a lay health worker delivered mental health promotion intervention delivered in primary schools which takes into account the social and cultural problems affecting the child, and involves all relevant stakeholders in the school, family and community (KIDS), which is currently being evaluated. Another good example which recently won the 'Turning the World Upside Down' award (http://www. ttwud.org/) and has shown promising early results, is the Dream-a-World Cultural Therapy in Jamaica (DAW). The programme promotes resilience, self-esteem and academic achievement through afterschool and summer camps for children with severe disruptive disorders and academic underachievement (Guzder et al. 2013).

An understanding of social determinants can also be used to more effectively screen the population for those at the greatest risk. For example, the Perinatal Mental Health Project in South Africa integrates mental health care into routine antenatal and post natal care, with women who have three or more risk factors for mental illness (such as HIV positive status and suffering domestic abuse), and those who screen positive for depression, referred to counsellors for therapy (Honikman et al. 2012).

Interventions for people with mental health problems must also be holistic, including social, economic and biomedical components. These interventions hold the possibility of enabling long term recovery thereby contributing powerfully to sustainable development. Good examples include the Mental Health and Development Model implemented by BasicNeeds which has shown improvements in mental health, social functioning and economic outcomes in rural 
Kenya (Lund et al. 2013), and the Banyan (The Banyan) who run clinical and social services for people with mental health problems living in poverty or homelessness in Tamil Nadu in India. The social services include employment and disability allowance support, social benefits and housing support. Unfortunately, few of these more holistic programmes have been rigorously evaluated, so their effect on both mental health outcomes and wider social and economic status is not proven. The first randomised controlled trial of CBR for schizophrenia is currently underway in Ethiopia, but results are not due until 2016 (RISE).

Box 1. Recommendations for policy and practice.

Recommendations for research

(1) Development, validation and dissemination of culturally appropriate mental health assessment tools to enable the mental health impacts of non-mental health programmes to be more easily measured.

(2) Conduct rigorous evaluations of mental health and broader development programmes to understand the impact of such programmes on mental health and on social and economic development, including modelling the macro-economic consequences of these interventions.

\section{Recommendations for policy and practice}

(1) Development agencies should ensure that they have equity for mental health in all their policies and also ensure that programmes do not have negative unintended consequences on mental health. There are several approaches and tools for assessment of policies impact on health equity for physical health which could be adapted for mental health (WHO \& Calouste Gulbenkian Foundation, 2014).

(2) Development agencies should measure the impact of their existing programmes on mental health, using available culturally valid assessment tools.

(3) Increase investment in the development and scale up of mental health promotion programmes, as preventing mental health problems from developing will have the biggest impact on sustainable development.

(4) Increase investment for mental health programmes that promote holistic recovery and therefore have the greatest impact on sustainable development.

As can be seen from the examples listed above, there is an increasing number of holistic programmes addressing the social determinants and consequences of mental illness being implemented in low and middle income countries. Scaling up these programmes could have an important impact on promoting sustainable development. Until recently it was almost impossible to get reliable information about these programmes, or even to know that they exist. The Mental Health Innovation Network (www.mhinnovation.net) website contains a growing database of over 100 systematically documented mental health programmes which are either in the process of or have been evaluated. Such a resource is vital not only for the mental health community, but also to demonstrate to the wider development sector where cost-effective solutions to mental health problems exist (Box 1).

\section{Conclusion}

Including mental health in the SDGs will not be a panacea for the vast under-investment in mental health globally. The Millennium Development Goals have been a mixed blessing with a largely vertical approach to single issues which has excluded key cross-cutting issues such as mental health. The SDGs bring the promise of a more holistic approach to development. It is now the task of global mental health to demonstrate not just that mental health is an integral part of sustainable development, but that affordable and effective solutions exist which can improve not just mental health, but development more broadly.

\section{Acknowledgements}

The author would like to thank Crick Lund for comments on a draft of this manuscript. With thanks to members of the Mental Health Innovation Network who constructed the database of innovations: Lucy Lee, Grace Ryan, Marguerite Regan and Shamaila Usmani.

\section{Financial Support}

Mary De Silva is supported by a Wellcome Trust/ LSHTM fellowship. The finders played no role in the conceptualisation or writing of this editorial. This editorial is an output of the Programme for Improving Mental health carE (PRIME). The material has been funded by UK aid from the UK Government; however, the views expressed do not necessarily reflect the UK Government's official policies.

\section{Statement of Interest}

The author declares no conflicts of interest.

\section{References}

BasicNeeds. Accessed November 2014 from http:// mhinnovation.net/innovation/basic-needs-international/.

Bloom DE, Cafiero ET, Jane-Llopis E, Abrahams-Gessel S, Bloom LR, Fathima S, Feigl AB, Gaziano T, Mowafi M, Pandya A, Prettner K, Rosenberg L, Seligman B, Stein 
AZ, Weinstein C (2011). The Global Economic Burden of Non-communicable Diseases. World Economic Forum: Geneva.

Cohen A, Eaton J, Radtke B, George C, Manuel V, De Silva M, Patel V (2011). Three models of community mental health services in low-income countries. International Journal of Mental Health Systems 5, 3.

DAW. Dream-a-World Cultural Therapy for Primary School Children in Jamaica [Online]. Accessed November 2014 from http://mhinnovation.net/innovations/dream-world-culturaltherapy-primary-school-children.

De Silva M, Roland J, On behalf of the Global Health and Mental Health All Party Parlimentary Groups (2014). Mental Health for Sustainable Development. The Global Health and Mental Health All Party Parilmentary Groups: London.

Eaton J, De Silva M, Regan M, Lamichhane J, Thornicroft G (2014). There is no wealth without mental health. The Lancet Psychiatry 1, 252-253.

Fekadu A, Medhin G, Kebede D, Alem A, Cleare AJ, Prince M (2015). Excess mortality in severe mental illness: 10-year population-based cohort study in rural Ethiopia. The British Journal of Psychiatry 206, 1-8.

Flisher AJ, Lund C, Funk M, Banda M, Bhana A, Doku V, Drew N, Kigozi F, Knapp M, Petersen I, Green A (2007). Mental health policy development and implementation in four African countries. Journal of Health Psychology 12, 505-516.

Gunnell D, Fernando R, Hewagama M, Priyangika WD, Konradsen F, Eddleston M (2007). The impact of pesticide regulations on suicide in Sri Lanka. International Journal of Epidemiology 36, 1235-1242.

Guzder J, Paisley V, Robertson-Hickling H, Hickling F (2013). Promoting resilience in high-risk children in Jamaica: a pilot study of a multimodal intervention. Canadian Academy of Child and Adolescent Psychiatry 22, 125-130.

Honikman S, van Heyningen T, Field S, Baron E, Tomlinson M (2012). Stepped care for maternal mental health: a case study of the perinatal mental health project in South Africa. PLoS Medicine 9.

House of Commons International Development Committee (2014). Disability and Development. Stationary Office: London.

KIDS. Kenya integrated intervention model for dialogue and screening to promote children's mental wellbeing [Online]. Accessed November 2014 from http://mhinnovation.net/ innovations/kids-kenya-integrated-intervention-modeldialogue-and-screening-promote-childrens-mental.

Kleinman A (2009). A failure of humanity. The Lancet 374, 603-604.

Kohn R, Saxena S, Levav I, Saraceno B (2004). The treatment gap in mental health care. Bulletin of the World Health Organisation 82, 858-866.

Lund C (2013). Poverty and mental health: a review of practice and policies. Neuropsychiatry 2, 213-219.

Lund C, De Silva MJ, Plagerson S, Cooper S, Chisholm D, Das J, Knapp M, Patel V (2011). Poverty and mental disorders: breaking the cycle in low-income and middle-income countries. The Lancet 378, 1502-1514.

Lund C, Tomlinson M, De Silva MJ, Fekadu A, Shidhaye R, Jordans M, Petersen I, Bhana A, Kigozi F, Prince M, Thornicroft G, Hanlon C, Kakuma R, McDaid D, Saxena S, Chisholm D, Raja S, Kippen-Wood S, Honikman S, Fairall L, Patel V (2012). PRIME: a programme to reduce the treatment gap for mental disorders in five low- and middle-income countries. PLoS Medicine 9, e1001359.

Lund C, Waruguru M, Kingori K, Kippen-Wood S, Breuer E, Mannarath S, Raja S (2013). Outcomes of the mental health and development model in rural Kenya: a 2-year prospective cohort intervention study. International Health $\mathbf{5}$, 43-50.

Miranda J, Patel V (2005). Achieving the millennium development goals: does mental health play a role? PLoS Medicine 2.

Nakimuli-Mpungu E, Alderman S, Kinyanda E, Allden K, Betancourt T, Alderman J, Pavia A, Okello J, Nakku J, Adaku A, Musis S (2013). Implementation and scale-up of psycho-trauma centers in a post-conflict area: a case study of a private-public partnership in Northern Uganda. PLoS Medicine $\mathbf{1 0 .}$

PCAF. Peter C Alderman Foundation Trauma Clinics [Online]. Accessed November 2014 from http:// mhinnovation.net/innovations/peter-c-aldermantrauma-clinics.

Pearlin LI (1989). The sociological study of stress. Journal of Health and Social Behavior 30, 241-256.

Plagerson S (2014). Integrating mental health and social development in theory and practice. Health Policy and Planning 1-8.

Raja S, Underhill C, Shrestha P, Sunder U, Mannarath S, Wood S, Patel V (2012). Integrating mental health and development: a case study of the BasicNeeds model in Nepal. PLoS Medicine 9.

RISE. Rehabilitation Intervention for people with Schizophrenia in Ethiopia [Online]. Accessed November 2014 from www. mhinnovation.net/innovations/RISE.

Rose G (1992). The Strategy of Preventive Medicine. Oxford University Press: Oxford.

Sen A (1999). Development as Freedom. Oxford University Press: Oxford.

The Banyan. Accessed November 2014 from http:// mhinnovation.net/innovations/banyan.

Thornicroft G (2013). Premature death among people with mental illness. British Medical Journal 346.

Thornicroft G, Patel V (2014). Including mental health among the new sustainable development goals. British Medical Journal 349, g5189.

Whiteford HA, Degenhardt L, Rehm J, Baxter AJ, Ferrari AJ, Erskine HE,., Charlson FJ, Norman RE, Flaxman AD, Johns N, Burstein R, Murray CJL, Vos T (2013). Global burden of disease attributable to mental and substance use disorders: findings from the Global Burden of Disease Study 2010. Lancet 382, 1575-1586. 
WHO (2005). Promoting Mental Health: Concepts, Emerging Evidence, Practice. World Health Organization: Geneva. WHO (2010). Mental Health and Development: Targeting People with Mental Health Conditions as a Vulnerable Group. World Health Organization: Geneva.

WHO (2013a). Comprehensive Mental Health Action Plan 2013-2020. Sixty-Sixth World Health Assembly. Resolution WHA66/8. World Health Organization: Geneva.
WHO (2013b). Investing in Mental Health: Evidence for Action. World Health Organization: Geneva.

WHO (2013c). Suicide Prevention [Online]. World Health Organization. http://www.who.int/mental_health/ prevention/en/.

WHO, Calouste Gulbenkian Foundation (2014). Social Determinants of Mental Health. World Health Organization: Geneva. 